(C) CEDA/TU, 2015, US Library of Congress, Catalog Card No. : 79-915209, ISSN: 2091-0339

The Journal of Development and Administrative Studies (JODAS), Vol. 23(1-2), pp. 33-54

\title{
System Dynamics Modeling of Lighting Electricity Demand in the Urban Residential Sector of Nepal
}

\author{
- Iswor Bajracharya and Nawraj Bhattarai*
}

\begin{abstract}
A significant portion of the total electricity is consumed in the residential sector of Nepal, mainly for lighting purpose. In this study, a model has been developed using the concept of system dynamics to analyze the dynamics of the changes in the urban residential lighting electricity demand up to the year 2030. A system dynamics modeling tool, Venism, has been used for this purpose. This study is useful for the utilities of companies for the power capacity expansion planning. Altogether three different scenarios have been developed. They are Reference Scenario (Ref), LED Lamp (LL) Scenario and Incandescent Lamp Remove (ILR) Scenario. The study has shown that lighting electricity consumption has already been in the decreasing trend due to the increasing use of Clear Fluorescent Lamp (CFL) and will be the minimum somewhere in the year between 2021 and 2022. Only a small portion of the total electricity will be consumed for lighting the household in the urban residential sector of Nepal in the coming decade. Therefore, government should focus the urban energy efficiency program for other uses of electricity such as cooking, water heating and water pumping etc. so that a significant amount of electricity can be saved in the urban households of Nepal. This study has also shown that there is no difference between the use of CFL and LED lamps from the energy saving point of view. Therefore, like the case of incandescent lamp and CFL, there is no need to encourage the people to buy LED lamp instead of CFL.
\end{abstract}

Keywords: Lighting electricity, urban households, electricity consumption and lamps sub-model

JEL Classification: $\mathrm{Q}_{22}, \mathrm{Q}_{25}, \mathrm{Q}_{41}$ and $\mathrm{Q}_{47}$

\section{Introduction}

Urbanization is rapidly taking place in Nepal. In 1991, the total number of people living in the urban area of Nepal was 1.69 million (9.2\% of the total population) which increased to 3.22 million (13.9\% of the total population) in 2001 and 4.52 million (17\% of the total population)

\footnotetext{
* Dr. Bajracharya and Dr. Bhattarai are the faculty at Department of Mechanical Engineering, Central Campus, Institute of Engineering, Tribhuvan University, Nepal. Corresponding Address: iswor1@yahoo.com
} 
Bajracharya and Bhattarai: System Dynamics Modeling of Lighting Electricity Demand in the...

in 2011 [1]. This rapid urbanization has increased the number of households in the urban area, consequently, increasing the electricity consumption in the urban residential sector. Due to the low industrial base, significant amount of electricity is consumed in the residential sector. About $45 \%$ of the total national electricity supply is consumed in the residential sector alone [2], out of which, about $55 \%$ is consumed in the urban residential sector [3], mainly for lighting, using electric appliances and water pumping. Studies have shown that about $38 \%$ of the total electricity consumed in the urban residential sector is used only for lighting purpose [4].

Although significant amount of electricity is used in the urban area for lighting purpose, no study has been done yet to project and analyze the lighting electricity demand focusing on the urban residential sector of Nepal. All the previous studies so far done are related to only the projection of the aggregate energy or electricity demand. Amatya et al. [5] have analyzed the residential sector energy demand and supply of Nepal in spreadsheet. The focus of this study was on the fuelwood supply sustainability to fulfill the residential energy demand in Nepal. Pokharel [6] has developed the econometric model to project the future energy demand (including electricity) of Nepal for various sectors such as residential, industrial, service, transportation and agriculture sector. Although the author has modeled and projected the future electricity demand, that is the aggregate electricity demand for the entire sector of Nepal. Shrestha and Rajbhandari [7] have projected energy consumption including electricity for the period 2005 - 2050 in Kathmandu Valley using MARKet ALlocation (MARKAL) model. The focus of this study was to analyze the impact of sectoral energy consumption on the emissions of carbon dioxide and local air pollutants in the Kathmandu valley. Bhattarai [8] has projected the future energy demand including electricity demand of Nepal for the period 2005 to 2030 in Long-Range Energy Alternative Planning System (LEAP) framework. This study has also projected only the aggregate electricity demand for the entire sector of Nepal. Bhattrai et al. [9] have projected the aggregate energy demand for the commercial sector of Nepal in LEAP framework. The purpose of this study was to project the energy demand including the electricity demand only for the commercial sector of Nepal. Malla [10] has studied the household energy consumption pattern of Nepal focusing on the biomass energy and its impact on environmental emissions. Parajuli et al. [11] have projected the future energy demand of Nepal using econometric method. This study has also projected only the aggregate electricity demand for the entire sector of Nepal. Several parameters play a role in the electricity demand changes. Having the knowledge of this is important in understanding how and when the electricity demand will change in future. Therefore, the main objective of this study is to understand the dynamics of urban electricity consumption for lighting purpose in a better way and project the future lighting electricity and peak power demand using the concept of system dynamics.

System dynamics is a feedback-based modeling tool which originated from the work of Forrester [12]. It is used to model the complex systems that are nonlinear and are governed by feedbacks. System dynamics modeling is a powerful tool which helps the decision makers to simulate the results of the decision before taking decision [13]. It has been used throughout the world to 
solve the problems in various fields such as business, health, energy, environment, economics and many more. In the energy sector, it has been used to estimate future energy demand and greenhouse gas emission, for integrated energy planning and supply side management and related policy analysis.

Sterman [13] has proposed a system dynamics model to simulate the national energy economy interactions and analyze the transition of economy from depleting conventional fossil fuel to new renewable resources. This model covers all energy sectors and most parts of the U.S. economy. USA has developed system dynamics based Threshold 21 (T21) energy model to understand the energy issue and its relation with society, economy and environment in US. T21 is an integrated energy planning model [14]. Likewise, Energy 2020 is a system dynamics based energy planning model on national level and is used by US Environmental Protection Agency, Environment Canada, California Air Resources Board, the Canadian National Energy Board [15]. Naill et al. [16] have used system dynamics model to evaluate the cost-effectiveness of US energy policies to mitigate the global warming. Chi et al. [17] have studied the exploration, production and consumption of natural gas with respect to the gas price, tax policy and demand conditions in UK. Indonesia's energy security has been studied by Prambudia et al. [18] considering the energy import by modeling and simulating energy-related policies with system dynamics. The U.S. Department of Energy uses "IDEAS Model” to simulate a long-term policy of energy supply and demand [19]. This model was prepared using system dynamics modeling concept. Feng et al. [20] have used system dynamics model to analyze the energy consumption and $\mathrm{CO}_{2}$ emissions in Beijing, China.The long term behavior of liberalized power markets was studied using system dynamic model in Germany [21]. Qudrat-Ullah et al. [22] have used system dynamic model to analyze the electricity supply, resource and pollution emission in Pakistan. Likewise, urban residential energy demand has been analyzed in Nigeria using system dynamic modeling [23].

This paper has been organized as follows: the first section describes the background and objectives of the paper; second section deals with the methodology; the third section is about the result and finally discussion and conclusion are given in fourth section.

\section{Methods and Materials}

\subsection{Concepts of System Dynamics}

System dynamics model uses the concept of feedback to represent the behavior of the complex nonlinear system. In the system dynamics methodology, a problem or a system is first represented as a causal loop diagram. A causal loop diagram is a simple map of a system that shows how one variable affects another. The systems are represented and calculated with the help of Stock and Flow diagrams. Stock and Flow diagrams contain specific symbols and components representing the structure of a system. Stocks are variables that can be accumulated or depleted over time (think of a stock as a bathtub). Flows represent rates of change in a stock (think of a flow as a bathtub faucet, which adds to the stock, or a bathtub drain, which 
Bajracharya and Bhattarai: System Dynamics Modeling of Lighting Electricity Demand in the...

reduces the stock.). These diagrams also contain "clouds", which represent the boundaries of the problem or system in question.

\subsection{Assumption}

A model is a simplification of the real world. The purpose is not to model all the details of the electricity business but to model the important parts and structure of the system by making reasonable simplifications. For simplifying the model, assumptions are made. In this model, following assumptions are made:

a. Three types of lamp are used in the urban residential sector of Nepal. They are incandescent lamp, fluorescent tube light and Clear Fluorescent Lamp (CFL).

b. The average power rating of incandescent lamp is 80 Watt, fluorescent tube light is 40 Watt and that of CFL lamp is 10 Watt. During the reference scenario, only these three types of lights will be used.

c. During the policy scenario, LED lamp will be introduced from the year 2020 .

Table 1 presents the endogenous, exogenous and excluded variables in the model.

Table 1: Exogenous, endogenous and excluded variables

\begin{tabular}{|l|l|l|}
\hline \multicolumn{1}{|c|}{ Exogenous Variables } & \multicolumn{1}{|c|}{ Endogenous Variables } & \multicolumn{1}{c|}{ Excluded Variables } \\
\hline Crude birth \& death rate & Population & $\begin{array}{l}\text { Quality of lamp on market } \\
\text { share }\end{array}$ \\
\hline Urban population share & Number of urban household & Seasonal use hours of lamp \\
\hline Urban household size & Market share of different lamps & \\
\hline Price of lamp & Total lighting power demand & \\
\hline Average life of lamp & $\begin{array}{l}\text { Total lighting electricity } \\
\text { demand }\end{array}$ & \\
\hline $\begin{array}{l}\text { Average number of lamp } \\
\text { per household }\end{array}$ & & \\
\hline Use hours & & \\
\hline
\end{tabular}

\subsection{Model Structure}

In this study a system dynamics modeling tool, Venism, has been used for the modeling purpose. The simulation period is $2011-2030$. The population size, urban household number, household size, lamp power, lamp price and use hours are the key factors for the urban residential lighting electricity consumption. The model consists of three sub-models: population sub-model, market share of lamps sub-model, electricity consumption sub-model and balancing feedbackloop which represents the household behavior. The main causal relations of the models are presented in Figure 1 and detail stock-flow diagram is shown in Figure 2. The plus or minus sign indicates the positive or negative effect of one variable on the other variable. Each submodel is discussed below. 


\subsubsection{Population sub-model}

Population growth is the fundamental cause of the increase in urban household which ultimately increases urban electricity demand. The birth rate and death rate are the main factors in the growth of population. Therefore, these two variables are used as the exogenous variables in the population sub-model and are taken from Central Bureau of Statistics (CBS) report [24, 25] for the medium variant. Table 2 represents the crude birth and death rate of Nepal. The population is given by equation (1).

$$
P=P_{i}+\int\left(B_{R}-D_{R}\right) d t
$$

Where, $P_{i}, B_{R}, D_{R}$ and $P$ are the initial population base, birth rate, death rate and population at time $t$ respectively. The birth rate and death rate are calculated using equations (2) and (3).

$$
\begin{gathered}
B_{R}=P \times C B R \\
D_{R}=P \times C D R
\end{gathered}
$$

Where, CBR and CDR are crude birth rate and crude death rate respectively.

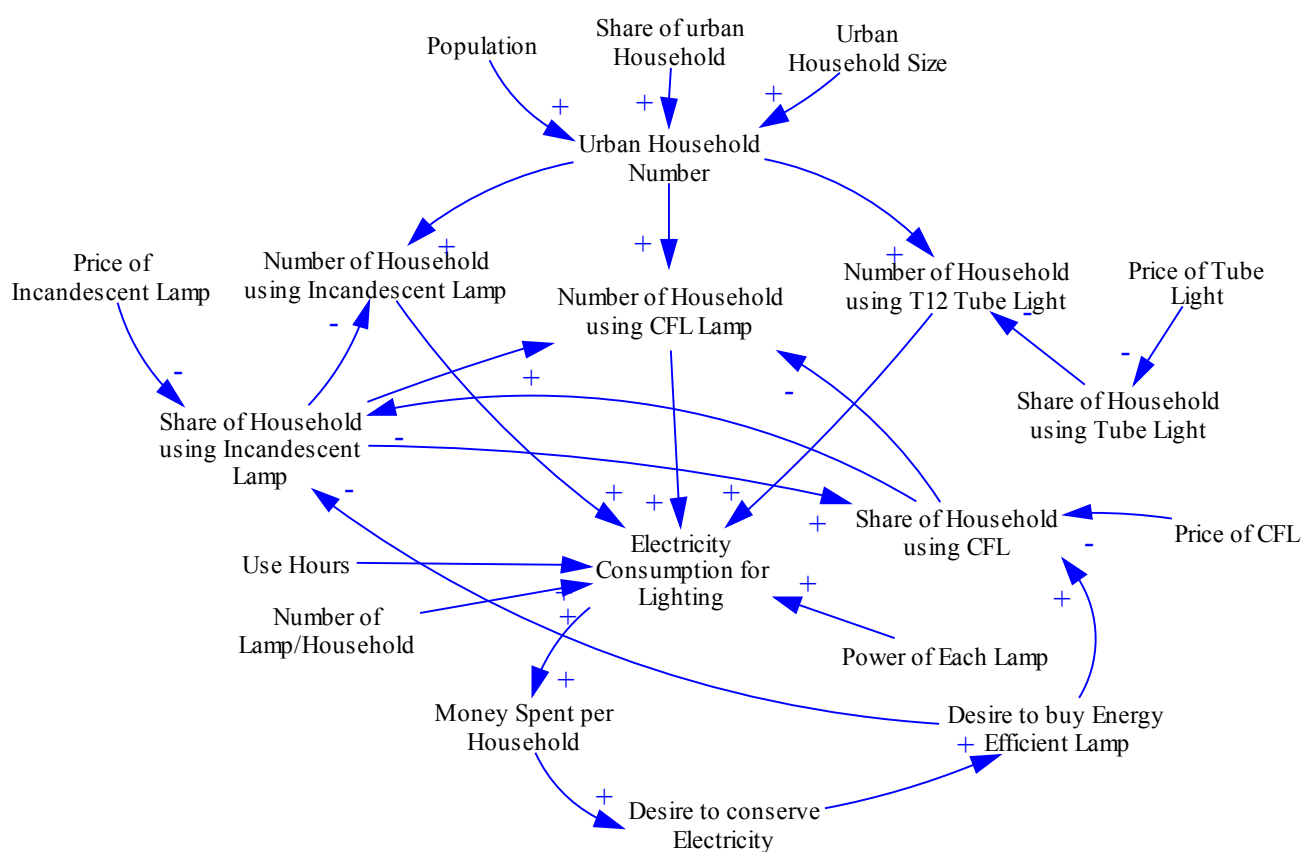

Figure 1: Main causal relations of the model

Likewise, the share of urban population has been used as an exogenous variable to model the evolution of urban population growth. The data of the urban population share has been taken 
from Central Bureau of Statistics (CBS) report [24, 25 ] for the medium variant and is given in Table 2. The detail stock-flow diagram of this population sub-model is presented in Figure 2. The mathematical relationships among these variables are given in the Appendix .

Table 2: The crude birth rate and death rate of Nepal [24,25]

\begin{tabular}{|l|c|c|c|c|c|c|c|}
\hline & \multicolumn{7}{|c|}{ Year } \\
\cline { 2 - 9 } & 2001 & 2006 & 2011 & 2015 & 2020 & 2025 & 2030 \\
\hline Crude Birth Rate per 1000 & 33.3 & 30 & 22.4 & 22.2 & 21 & 18.5 & 15.8 \\
\hline Crude Death Rate per 1000 & 10 & 8.7 & 7.4 & 7.2 & 7.2 & 6.9 & 6.7 \\
\hline Urban Population Share (\%) & 13 & 16.69 & 17.07 & 18.93 & 22.06 & 25.54 & 29.38 \\
\hline
\end{tabular}

\subsubsection{Market share of lamps sub-model}

At present, three types of lamps (incandescent, CFL and fluorescent tube) are common for lighting in the urban household of Nepal. Although there are some sales of LED lamp in the market, their use in the household for lighting has not become widespread yet due to their high prices. Therefore, it has been assumed that LED lamp will be within the reach of the common people only after 2020 in Nepal when the prices declines as projected by EIA [26]. The market share of each lamp is determined by the attractiveness of each lamp in relation to the attractiveness of other lamps in the market. Attractiveness represents the customer's affinity for buying the product and depends upon the number of variables such as price, quality, service, features, and so on. In this simple model, only the effect of price has been taken into account. The details of modeling the product attractiveness and market share can be found in [27]. The price attractiveness of a product is given by equation (4)

$$
A_{p}=e^{S_{p}\left(\frac{P}{P_{t h}}\right)}
$$

Where, $A_{p}, S_{p}, P$ and $P_{t h}$ are price attractiveness of lamp, sensitivity of attractiveness to the price, price of the lamp and threshold price of lamp respectively. The parameter $S_{p}$ controls the strength of the exponential growth effect of the product and $P_{t h}$ represents the size of the installed base above which the effect will be pronounced. The parameter $P$ and $S_{p}$ are used as the exogenous variables.

Table 3 presents the price of the lamp used in this study. The historical price of the lamp has been based on the personal experience whereas the future price has been used based upon the projection made by EIA [26]. 
Table 3: Price of different lamps

\begin{tabular}{|l|c|c|c|c|c|c|c|}
\hline \multirow{2}{*}{ Lamp Type } & \multicolumn{7}{|c|}{ Year } \\
\cline { 2 - 8 } & 2001 & 2006 & 2010 & 2015 & 2020 & 2025 & 2030 \\
\hline Incandescent Lamp Price (Rs) & 40 & 55 & 80 & 110 & 150 & 170 & 190 \\
\hline CFL Lamp Price (Rs) & 750 & 450 & 380 & 350 & 300 & 280 & 250 \\
\hline Fluorescent Tube Light (Rs) & 250 & 300 & 320 & 350 & 350 & 350 & 350 \\
\hline LED Lamp Price (Rs) & & & 3000 & 1190 & 580 & 350 & 300 \\
\hline
\end{tabular}

Likewise, the market share of each product is given by equation (5).

$$
\begin{gathered}
M_{i}=\frac{A_{p, i}}{T_{A}} \\
T_{A}=\sum_{i=1}^{n} A_{p, i}
\end{gathered}
$$

Where, $M_{i}, A_{p, i}$ and $T_{A}$ represent the market share of lamp type $i$, price attractiveness of lamp $i$ and total price attractiveness of all the lamp types respectively.

The number of urban household has been modeled using the average household size as an exogenous variable. Since the literatures related to the projection of urban household size are not available, the assumption has been made as shown in Table 4 based on the historical trend. The number of urban household is given by the equation (6).

$$
H_{u}=\frac{P_{u}}{H_{s}}
$$

Where, $H_{u}, P_{u}$ and $H_{s}$ represent the urban household number, urban population size and average urban household size. The mathematical relationships among these variables are given in the Appendix. The detail stock-flow diagram of this sub-model is presented in Figure 2.

Table 4: Urban Household Size in Nepal

\begin{tabular}{|l|c|c|c|c|c|c|c|}
\hline \multirow{2}{*}{ Size } & \multicolumn{7}{|c|}{ Year } \\
\cline { 2 - 9 } & 2001 & 2006 & 2011 & 2015 & 2020 & 2025 & 2030 \\
\hline Average urban household size & 5 & 4.4 & 4.32 & 4.25 & 4.15 & 4 & 3.9 \\
\hline
\end{tabular}

\subsubsection{Electricity consumption sub-model}

This sub-model captures the stock of the various lamps to compute the electricity consumption. Other things remain unchanged; the stock of the lamp at any time depends upon the difference between the rate of purchase of new lamps and the expiry of the used lamps. The purchase of new lamps is a function of the average number of lamps per household, number of new household and the number of old household. Likewise, the expiry of lamp depends upon the average life of the lamp. When the stock of each lamp type is multiplied by the average power of lamp, the total installed power of lamp is ascertained. The sum of the total power of 
Bajracharya and Bhattarai: System Dynamics Modeling of Lighting Electricity Demand in the...

each lamp type provides the total peak power demand of lamp. When the total lamp power is multiplied by the average use hours, the total electricity consumption is obtained.

Average number of lamps per household, average power and average life of lamp are used as the exogenous variables and the values of these variables are given in Table 5. The detail stock-flow diagram of this population sub-model is presented in Figure 2. The mathematical relationships among these variables are given in the Appendix.

Table 5: Average number of lamps per household, average power and expected average life of different lamps

\begin{tabular}{|l|c|c|c|c|}
\hline Lamp Type & $\begin{array}{c}\text { Average number of } \\
\text { lamp /household }\end{array}$ & $\begin{array}{c}\text { Average Lamp } \\
\text { Power (W) }\end{array}$ & $\begin{array}{c}\text { Average } \\
\text { Use } \\
\text { Hours }\end{array}$ & $\begin{array}{c}\text { Average Life } \\
\text { (Hours) [28, } \\
\text { 29] }]\end{array}$ \\
\hline Incandescent Lamp & 5 & 80 & 5 & 1,000 \\
\hline CFL & 5 & 10 & 5 & 8,000 \\
\hline Fluorescent Tube Light & 5 & 40 & 5 & 10,000 \\
\hline LED Lamp & 5 & 10 & 5 & 25,000 \\
\hline
\end{tabular}

\subsubsection{Balancing Feedback Loop}

This feedback loop controls the household money on electricity bill and ultimately leads to the use of energy efficient lamp to reduce the electricity consumption and save electricity bill. The major parameters are unit cost of electricity, average annual income per household and elasticity of demand for energy efficient lamp. The average annual income per household has been taken as Rs. 3,88,032 [30] and the average cost of electricity per kWh has been taken as Rs. 8 , the present cost. No literature has been found regarding the elasticity of demand for energy efficient lamp in the context of Nepal. So its value has been assumed 0.2. During the calibration process, when its value was varied along with the per unit price of electricity, it was found that it has almost no effect on the energy demand. In fact, this feedback loop has very small effect on the energy demand. The reason is that the annual cost of lighting electricity compared to the annual income is very small. The mathematical equations among these variables are given in Appendix.

\subsubsection{Scenario Development}

Energy scenarios refer to a set of events or energy pathways that are strategically designed to see the effect of particular issue or policy [31]. In this study, three different scenarios have been developed. The Reference (Ref) scenario indicates the continuance of the existing trend and policies in future as well. Therefore, it has been assumed that only three types of lamps (incandescent, CFL and fluorescent tube light) will have market share in Nepal till 2030. In LED Lamp (LL) scenario, it has been assumed that the market share of LED lamp will be widespread only after 2020. In Incandescent Lamp Remove (ILR) scenario, it has been assumed that the use of incandescent lamp will be banned by the government from 2020. The electricity consumption in different scenarios will be compared with the reference scenario. 


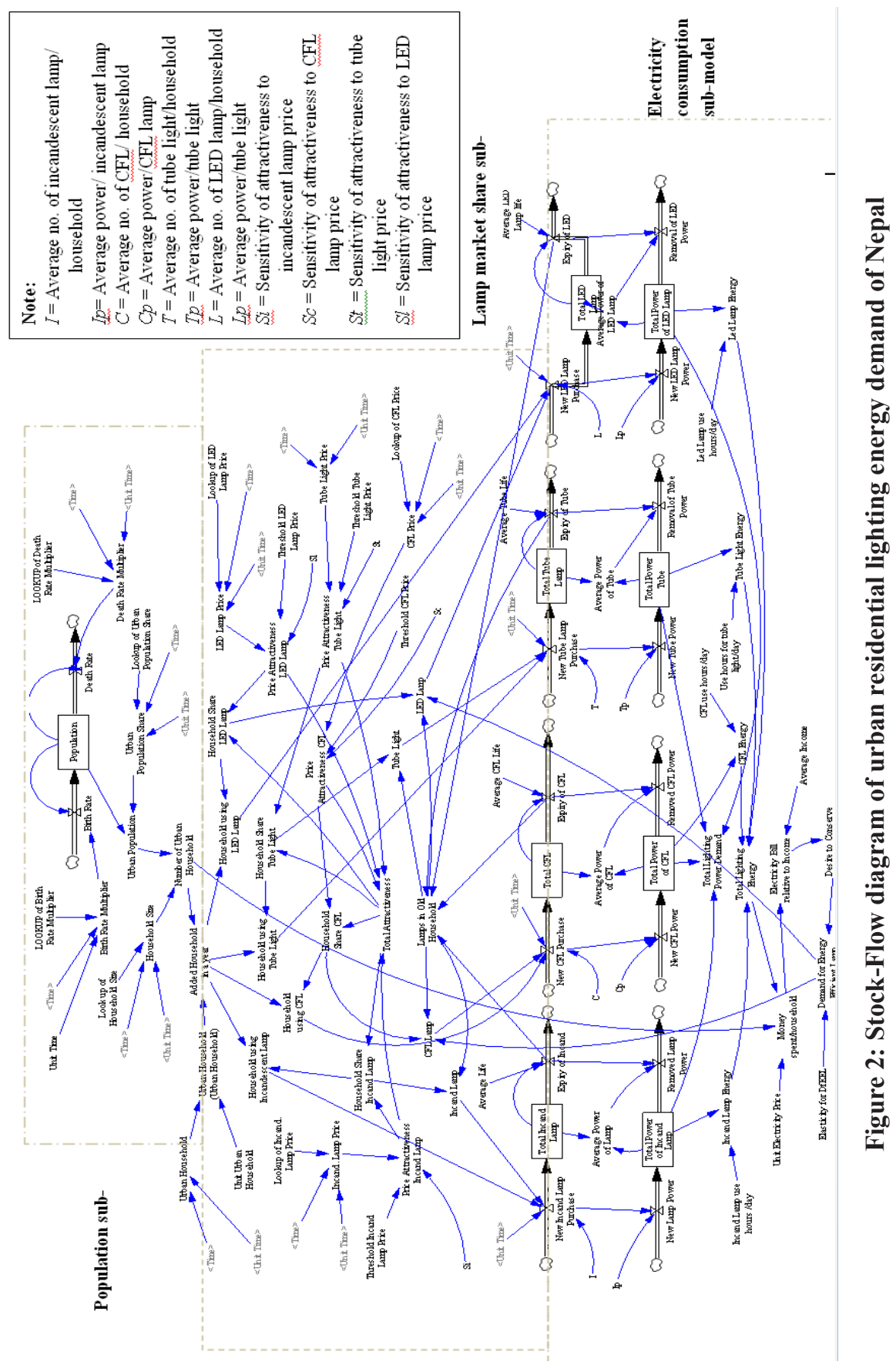




\subsubsection{Model Calibration}

The model has been calibrated using the historical data of urban population, urban household and lighting electricity consumption for the year 2001 and 2011 as the historical data are available only for these two years. The population and household data are taken from Nepal Population Report and Nepal Population \& Housing Census 2011 [24,25]. The urban lighting electricity consumption data are taken from Water and Energy Commission Secretariat (WECS), Government of Nepal Report [1, 2, 3].

The variables used for calibration are crude birth rate and death rate, urban population share, household size, threshold lamp price, sensitivity of attractiveness to the lamp price and elasticity of demand for energy efficient lamp. The comparison between the historical data and simulated data has been presented in Table 6 which shows the very close agreement between them. After calibration, the result of urban population from the model has been compared with the urban population projection by Central Bureau of Statistics (CBS) [25]. Table 7 shows the population comparison result.

Table 6: Comparison of historical and simulated results

\begin{tabular}{|c|c|c|c|c|c|c|c|c|c|}
\hline & \multicolumn{3}{|c|}{ Urban Population } & \multicolumn{3}{c|}{ Urban Household } & \multicolumn{3}{c|}{$\begin{array}{c}\text { Lighting Energy } \\
\text { Consumption (GWh) }\end{array}$} \\
\hline Year & H & S & D (\%) & H & S & D (\%) & H & S & D (\%) \\
\hline 2001 & $3,227,879$ & $3,164,091$ & 1.98 & 552,919 & 547,215 & 1.03 & 184 & 184.04 & -0.02 \\
\hline 2011 & $4,523,820$ & $4,563,003$ & -0.87 & $1,047,297$ & $1,002,719$ & 4.26 & 268.8 & 268.7 & 0.03 \\
\hline
\end{tabular}

Note: H : Historical data, S: Simulated data, D: Deviation between historical and simulated data

Table 7: Comparison of urban population projection by model and CBS projection

\begin{tabular}{|l|c|c|c|c|c|}
\hline Year & 2011 & 2015 & 2020 & 2025 & 2030 \\
\hline Model Projection & $4,563,030$ & $5,346,630$ & $6,589,530$ & $8,134,180$ & $9,783,710$ \\
\hline CBS Projection & $4,523,821$ & $5,308,930$ & $6,615,881$ & $8,125,202$ & $9,793,908$ \\
\hline
\end{tabular}

\section{Result and Discussion}

The calibrated model has been used for different scenarios. For each scenario, the changes in the future lighting electricity demand in the urban household have been presented.

\subsection{Reference (Ref) Scenario}

Figure 3 shows the changes in the future electricity demand for lighting in the urban household of Nepal. This figure shows that the lighting energy consumption was in the increasing trend till 2006, then peaked during 2007 and 2008 ( $295 \mathrm{GWh}$ ). The consumption then followed a decreasing trend. The demand will be minimum in the year $2022(121 \mathrm{GWh})$ and then again will follow a increasing trend very slowly. The electricity demand will be $134 \mathrm{GWh}$ in the year 2030 . 


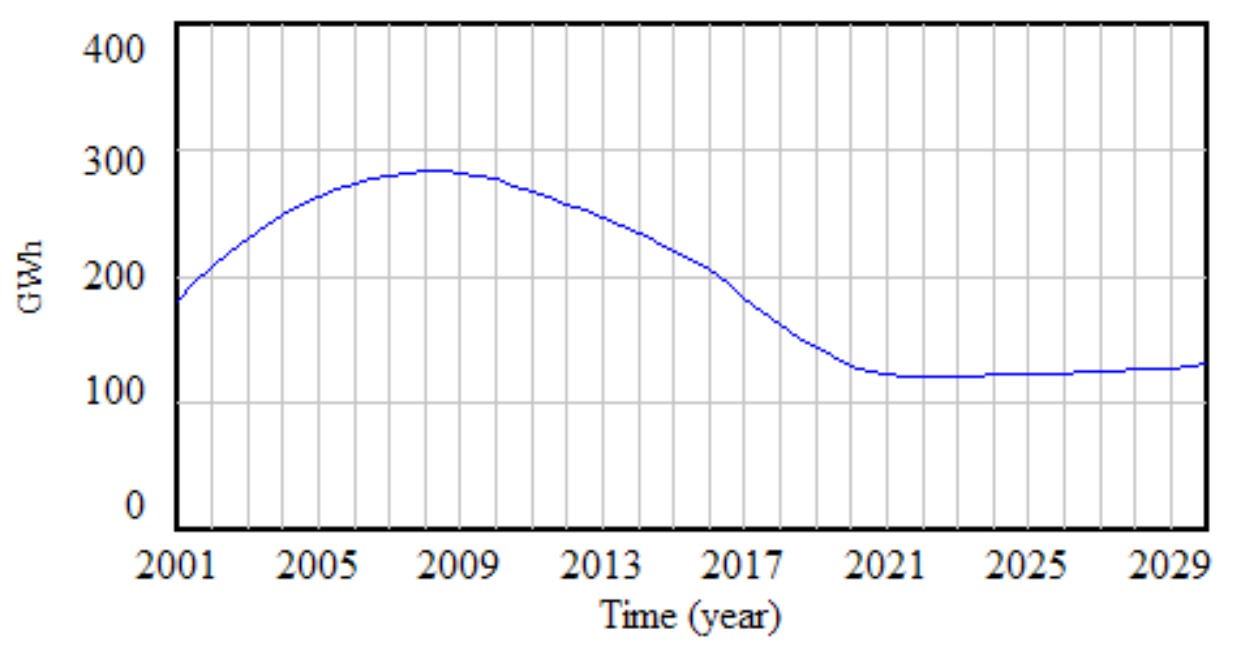

Total Lighting Energy : Reference Scenario

Figure 3: Total lighting energy demand in urban household of Nepal in Reference Scenario

Figure 4 shows the changes in the peak lighting power demand. The maximum peak power demand was 397 MW in 2007 and 2008 which gradually decreased with the use of CFL. The peak power demand will be $180 \mathrm{MW}$ in 2030.

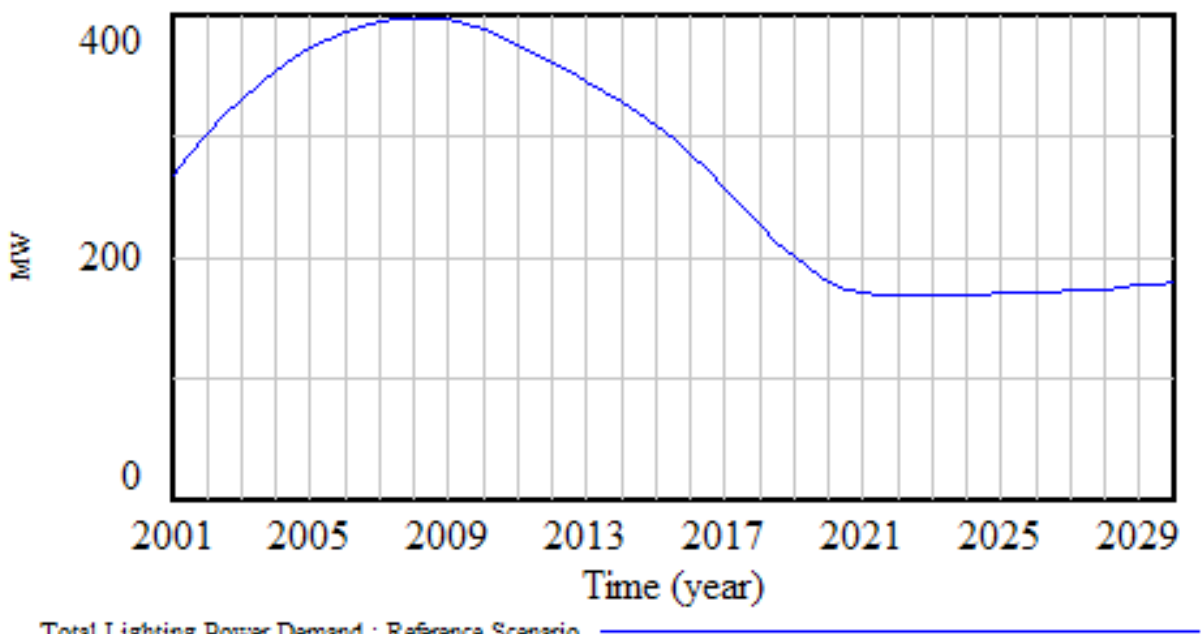

Figure 4: Peak lighting power demand in Reference scenario 
Figure 5 presents the dynamics of the changes in the electricity consumption in Incandescent lamp, CFL and Fluorescent tube light from 2001 to 2030. This figure shows that as the electricity consumed by CFL has increased from the year 2007, the electricity consumed by incandescent lamp has gradually started decreasing.

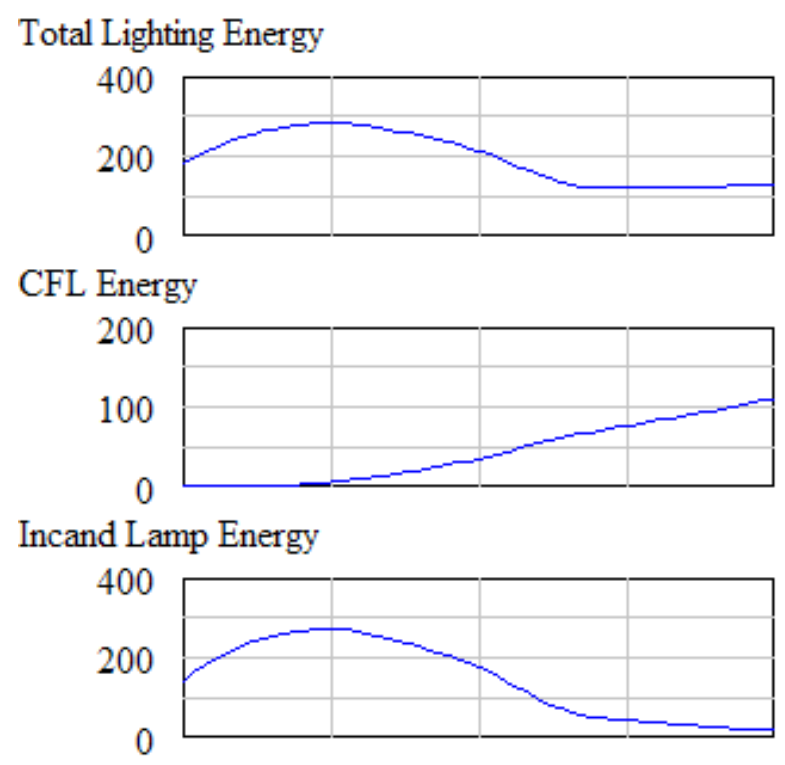

Tube Light Energy

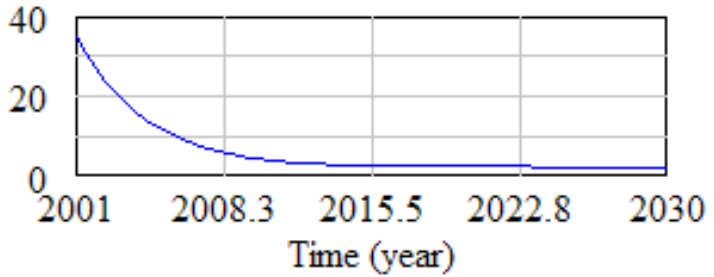

Figure 5: Dynamics of the changes in the lighting electricity consumption (GWh) in different types of lamp in Reference Scenario

\subsection{LED Lamp (LL) Scenario}

Figure 6 shows the comparison of future lighting electricity demand in the urban household of Nepal in LED Lamp and Reference scenarios. Due to the introduction of LED lamp, the total electricity demand has slightly reduced in this scenario compared to the Reference scenario. Table 8 shows the future electricity demand in this scenario in comparison with the Reference scenario. 
Table 8: Comparison of lighting electricity demand (GWh) in LL and Ref Scenarios

\begin{tabular}{|c|c|c|c|c|c|c|}
\hline \multirow{2}{*}{ Scenario } & \multicolumn{6}{|c|}{ Year } \\
\cline { 2 - 7 } & 2020 & 2022 & 2024 & 2026 & 2028 & 2030 \\
\hline Reference Scenario & 136 & 121 & 123 & 125 & 130 & 134 \\
\hline LED Lamp Scenario & 136 & 121 & 122 & 124 & 126 & 130 \\
\hline
\end{tabular}

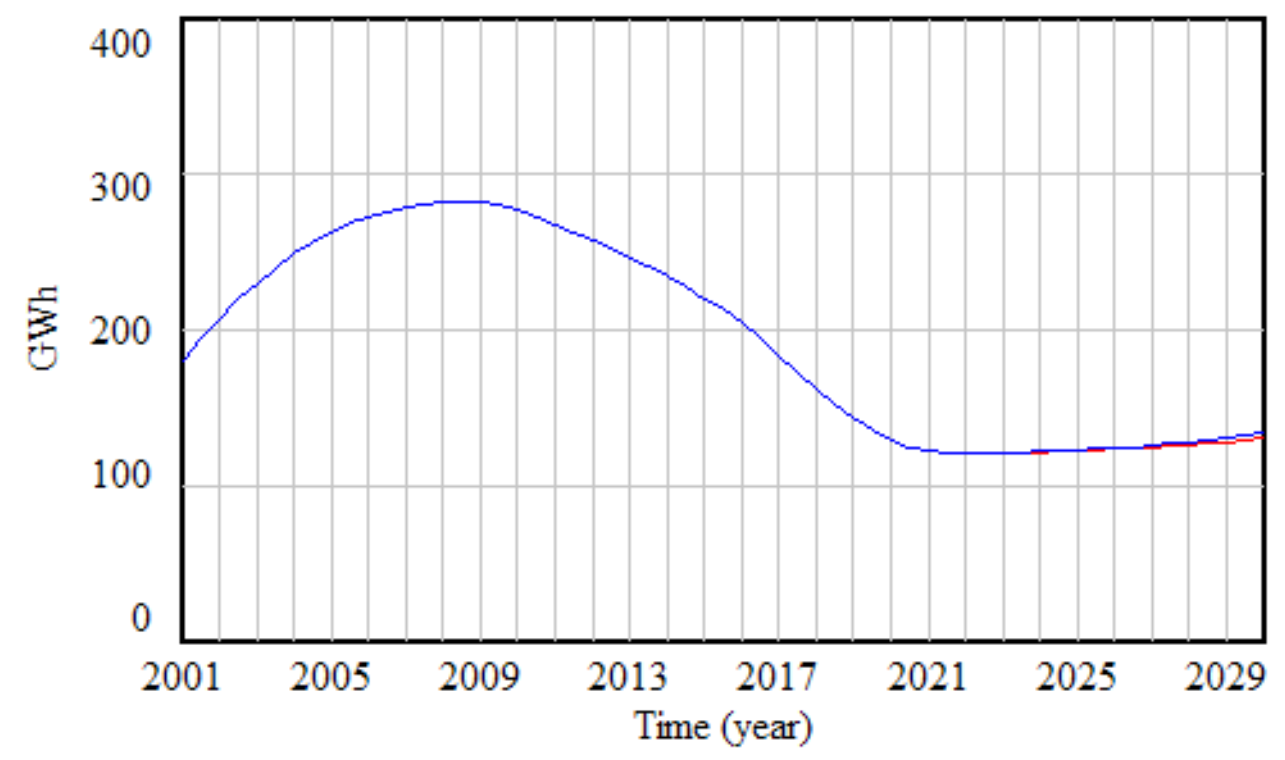

Total Lighting Energy : Reference Scenario

Total Lighting Energy : Led Lamp Scenario

Figure 6: Comparison of lighting energy demand in urban household in LED Lamp and Reference Scenario

\subsection{Incandescent Lamp Remove (ILR) Scenario}

If the use of incandescent lamps is banned from the year 2020, the dynamics of the changes in the lighting electricity and peak power demand will be as presented in Figure 7 and Figure 8 respectively. The electricity demand will be drastically reduced in this scenario compared to the LLR scenario. Figure 9 shows how the ban on the use of incandescent lamp will bring changes in the electricity consumption in CFL. It can be seen that as the incandescent lamps are banned, the sales of the CFL will increase suddenly and therefore, the electricity consumption in CFL will increase sharply as shown in this figure. The total lighting electricity demand will be only 113 GWh in this scenario compared to $134 \mathrm{GWh}$ in Ref scenario by 2030. 
Bajracharya and Bhattarai: System Dynamics Modeling of Lighting Electricity Demand in the...

Table 9: Comparison of lighting electricity demand (GWh) in ILR and Ref Scenarios

\begin{tabular}{|l|c|c|c|c|c|c|}
\hline \multirow{2}{*}{\multicolumn{1}{|c|}{ Scenario }} & \multicolumn{6}{c|}{ Year } \\
\cline { 2 - 7 } & 2020 & 2022 & 2024 & 2026 & 2028 & 2030 \\
\hline ILR Scenario & 129 & 81 & 89 & 97 & 105 & 113 \\
\hline Reference Scenario & 136 & 121 & 123 & 125 & 130 & 134 \\
\hline
\end{tabular}

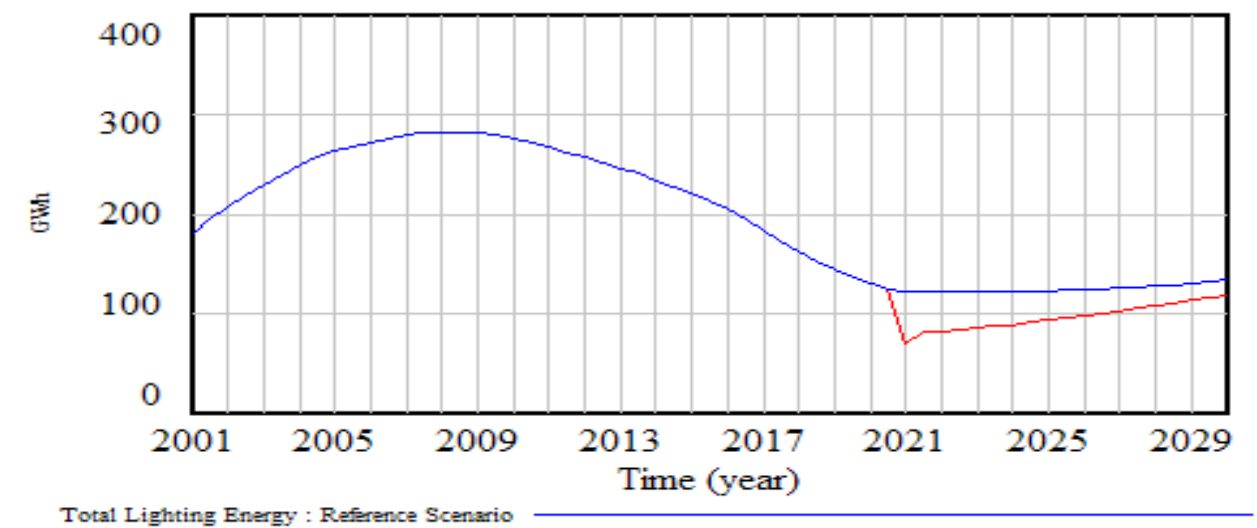

Total Lighting Energy : Incandescent Lamp Remove Scenario

Figure 7: Comparison of lighting energy demand in urban household in ILR and Ref Scenarios

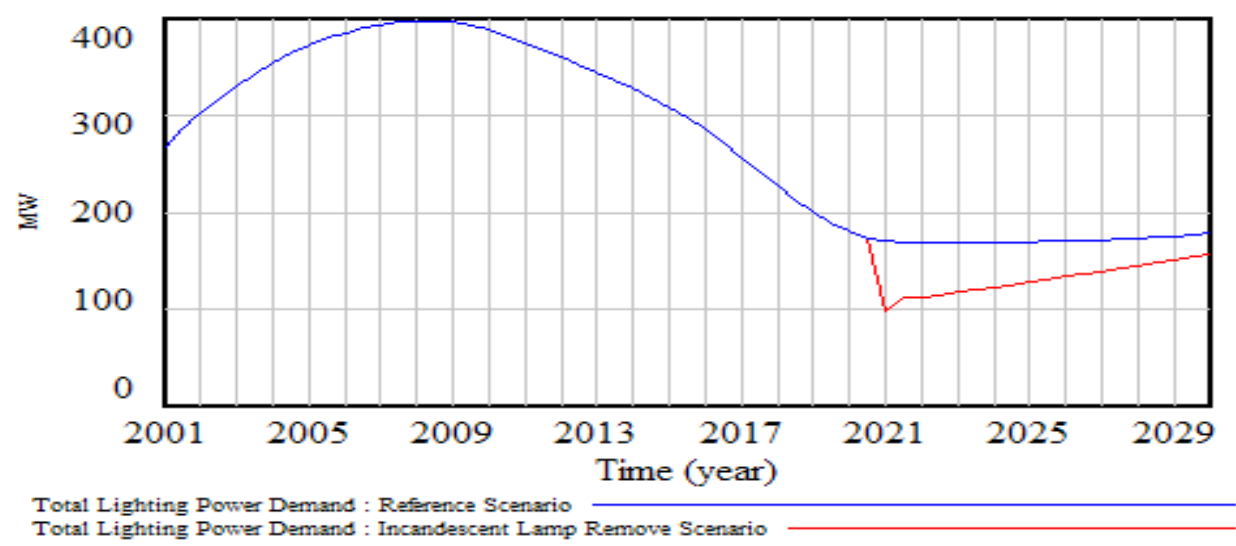

Figure 8: Peak lighting power demand in Reference scenario 


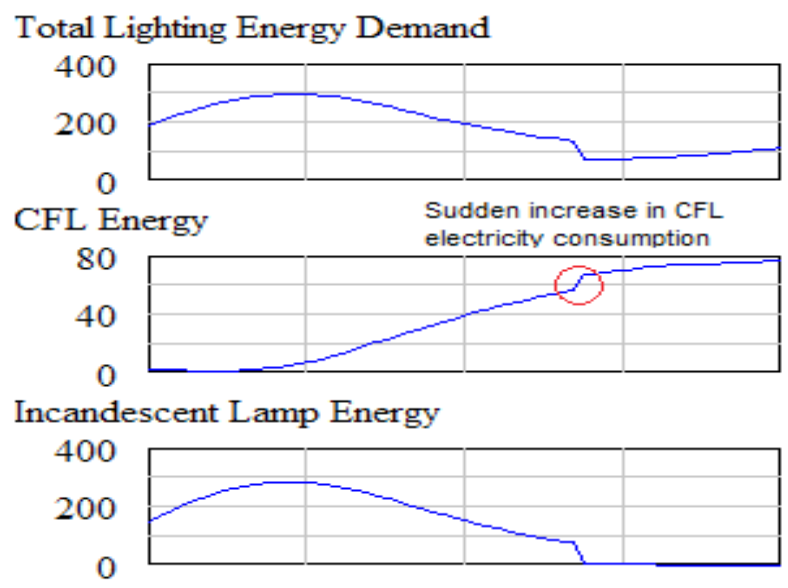

Tube Light Energy

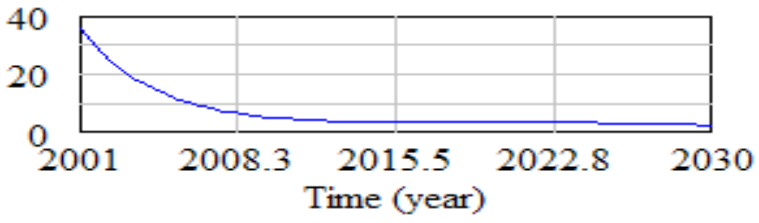

Figure 9: Dynamics of the changes in the electricity consumption (GWh) in ILR Scenario

\section{Concluding Remarks}

This study has analyzed and presented how the lighting electricity demand will be changed in the urban residential sector of Nepal over the period till 2030. This information is useful for the utilities of companies for future power capacity expansion planning. Of the many parameters, the price of the lamp is a major factor that determines the market share of the particular lamp. The rapid decline in the price of the CFL during the last one decade has increased the market share of the CFL and decreased the share of incandescent lamp. Therefore, the lighting electricity consumption is in the decreasing trend and will be the minimum somewhere in the year between 2021 and 2022, thereafter, slowly starts increasing. Therefore, all the energy efficiency programs to be conducted by the government which are meant to save the electricity should be aimed at other uses of electricity such as water heating, cooking, pumping etc. Although LED lamps have become popular in the developed countries because of its longer life, the high cost of this lamp has made very slow market penetration in many under-developed countries like Nepal. The LL scenario has shown that the saving in the electricity due to the 
introduction of LED lamp is only marginal. Therefore, like the case of incandescent lamp and CFL, there is no need to encourage the people to buy LED lamp instead of CFL.

\section{Acknowledgement}

The authors would like to acknowledge three anonymous reviewers for going through the manuscript and providing valuable and fruitful comments to improve the quality of this article.

\section{Appendix}

\section{Population sub-model}

- $\quad$ Population $=$ Initial Population $+\int($ Birth Rate- Death Rate $) d t$

- Birth Rate $=$ Population $\times$ Birth Rate Multiplier

- Death Rate $=$ Population $\times$ Death Rate Multiplier

- Birth Rate Multiplier = Lookup of Birth Rate Multiplier (Time/Unit Time)

- Lookup of Birth Rate Multiplier([(2001, 0.033)-(2030,0.0158)], (2001,0.033), (2006,0.03), (2011, 0.0224), (2016, 0.0222), (2020, 0.021), (2025, 0.0185), (2030, $0.0158)$ )

- $\quad$ Unit Time $=1$

- $\quad$ Death Rate Multiplier = Lookup of Death Rate Multiplier(Time/Unit Time)

- Lookup of Death Rate Multiplier ([(2001,0.001)-(2030,0.0067)],(2001,0.001),(2006 ,0.0087),

(2011,0.0074),(2015,0.0072),(2020,0.0072),(2025,0.0069),(2030,0.0067))

- Urban Population $=$ Population $\times$ Urban Population Share

- Household Size = Lookup of Household Size (Time/Unit Time)

- Household Size (Household Size) $=$ Household Size $\times$ Unit Household Size

- $\quad$ Unit Household Size = 1

- Number of Urban Household = Urban Population / Household size (Household Size)

\section{Market share of lamp sub-model}

- Lookup of Incand. Lamp Price ([(2001,40)- (2030,160)], (2001,40), (2010,80), (2015,100), (2020,120), (2025,140), (2030, 160))

- $\quad$ Unit Time $=1$ 
- Incand. Lamp Price = Lookup of Incand. Lamp Price (Time/Unit Time)

- $\quad$ Threshold Incand Lamp Price = 40

- Sensitivity of Attractiveness to the price $=-1.75$

- Price Attractiveness to Incand Lamp = exp(Sensitivity of Attractiveness to the price $\times$ (Incand. Lamp Price/Threshold Incand Lamp Price))

- Urban Household Share Incand Lamp = Price Attractiveness Incand Lamp/Total Attractiveness

- $\quad$ Lookup of CFL Price ([(2001,0)-(2050,800)],(2001,750),(2005,470),(2010,380), (2015,350),(2020,300),(2025,280),(2030,250))

- $\quad$ CFL Price = Lookup of CFL Price(Time/Unit Time)

- $\quad$ Threshold CFL Price $=250$

- $\quad$ Sensitivity of Attractiveness to CFL price $=-3$

- Price Attractiveness CFL $=\exp ($ Sensitivity of Attractiveness to $C F L$ price $\times(C F L$ Price/Threshold CFL Price))

- $\quad$ Lookup of Led Lamp Price ([(2010,4000)-(2040,300)],(2010,3000),(2012,1800), (2015,1193),(2017,825),(2020,580),(2025,350),(2030,300))

- $\quad$ Led Lamp Price =Lookup of Led Lamp Price (Time/Unit Time)

- $\quad$ Threshold Led Lamp Price $=300$

- Sensitivity of Attractiveness to Led Lamp Price = -6

- $\quad$ Lookup of Led Lamp Price ([(2010,4000)-(2040,300)],(2010,3000),(2012,1800), (2015,1193),(2017,825),(2020,580),(2025,350),(2030,300))

- $\quad$ Tube Light Price = Lookup of Tube Light Price(Time/Unit Time)

- $\quad$ Threshold CFL Price $=250$

- Sensitivity of Attractiveness to Tube Light price =-6

- Price Attractiveness Tube Light = exp(Sensitivity of Attractiveness to Tube Light price $\times($ Tube Light Price/Threshold Tube Light Price))

- $\quad$ Total Attractiveness = Price Attractiveness Incand Lamp + Price Attractiveness CFL + Price Attractiveness of tube light + Price Attractiveness Led Lamp

- Household Share Incand Lamp = Price Attractiveness Incand Lamp/Total Attractiveness

- Household Share CFL = Price Attractiveness CFL /Total Attractiveness

- Household Share Tube Light = Price Attractiveness Tube Light/Total Attractiveness

- Household Share LED Lamp = Price Attractiveness LED Lamp/Total Attractiveness 
50 Bajracharya and Bhattarai: System Dynamics Modeling of Lighting Electricity Demand in the...

- Household using Incandescent Lamp $=$ Added Household in a year $\times$ Household Share Incand Lamp

- Household using CFL = Added Household in a year $\times$ Household Share CFL

- Household using Tube Light $=$ Added Household in a year $\times$ Household Share Tube Light

- Household using LED Lamp = Added Household in a year $\times$ Household Share LED Lamp

- $\quad$ Lamps in Old Household = Expiry of Incand + Expiry of CFL + Expiry of Tube + Expiry of LED

- Incand Lamp = Lamps in Old Household $\times$ Household Share Incand Lamp

- $\quad$ CFL Lamp = Lamps in Old Household $\times$ Household Share CFL $\times(1+$ Demand for Energy Efficient Lamp)

- $\quad$ Tube Light $=$ Lamps in Old Household $\times$ Household Share Tube Light

- LED Lamp = Lamps in Old Household $\times$ Household Share LED Lamp $\times(1+$ Demand for Energy Efficient Lamp)

\section{Electricity consumption sub-model}

- New Incand Lamp Purchase = (Average No. of Incand Lamp/Household $\times$ Household using Incandescent Lamp)/Unit Time +Number of Incand Lamp/Unit Time

- Incand Lamp = New Incan Lamp Purchase-Expiry of Incand Lamp

- $\quad$ Expiry = Total Incand Lamp/Average Life

- New Lamp Power = Average Power/Lamp $\times$ New Incan Lamp Purchase

- $\quad$ Total Power of Incand Lamp = (New Lamp Power-Removed Lamp Power)

- $\quad$ Removed Lamp Power = Average Power of Lamp $\times$ Expiry of Incand Lamp

- Average No. of Incand Lamp/Household = 5

- Average Power /Incand Lamp $=80 \mathrm{~W}$

- New CFL Purchase = (Household using CFL $\times$ Average No. of CFL/Household $)$ / Unit Time + Number of CFL Lamp/Unit Time

- $\quad$ Total CFL $=$ New CFL Purchase-Expiry of CFL

- $\quad$ Expiry of CFL = Total CFL/Average CFL Life

- $\quad$ New CFL Power = Average power/CFL $\times$ New CFL Purchase

- $\quad$ Total CFL Power = New CFL Power-Removed CFL Power

- Average No. of CFL/Household $=5$

- Average Power $/ C F L=10 \mathrm{~W}$ 
- $\quad$ Removed CFL Power = Average Power of CFL $\times$ Expiry of CFL

- New Tube Light Purchase = (Household using Tube Light $\times$ Average No. of Tube Light/Household)/Unit Time + Number of Tube Light/Unit Time

- $\quad$ Total Tube Lamp = New Tube Lamp Purchase-Expiry of Tube

- $\quad$ Expiry of Tube = Total Tube Lamp/Average Tube Life

- New Tube Power = Average power/Tube Light $\times$ New Tube Light Purchase

- Total Tube Power = New Tube Power-Removal of Tube Power

- $\quad$ Average Power of Tube = Total Power Tube/Total Tube Lamp

- $\quad$ Removal of Tube $=$ Average Power of Tube $\times$ Expiry of Tube

- Average No. of Tube/Household = 5

- Average Power/Tube $=40 \mathrm{~W}$

- New LED Lamp Purchase = (Household using LED Lamp $\times$ Average No. of LED Lamp /Household)/Unit Time + Number of LED Lamp/Unit Time

- $\quad$ Total LED Lamp = New LED Lamp Purchase-Expiry of LED

- $\quad$ Expiry of LED = Total LED Lamp/Average LED Lamp life

- Average No. of LED Lamp/Household $=5$

- Average Power/LED Lamp $=10 \mathrm{~W}$

- Removal of LED Lamp = Average Power of LED Lamp $\times$ Expiry of Tube

- $\quad$ Total Lighting Power Demand = Total Power of CFL + Total Power of Incand Lamp + Total Power of LED Lamp + Total Power Tube

- $\quad$ Total Lighting Energy = (CFL Energy + Incand Lamp Energy + Led Lamp Energy + Tube Light Energy)

\section{Balancing Feedback Loop}

- $\quad$ Unit Electricity Price $=$ Rs. 8

- Money Spent/Household $=($ Total Lighting Energy $\times 1 e+006 \times$ Unit Electricity Price $) /$ (Number of Urban Household)

- $\quad$ Average Income = Rs.388,032

- Electricity Bill Relative to Income = Money spent/household/Average Income

- Desire to Conserve Electricity = Electricity Bill relative to Income

- $\quad$ Elasticity for DfEEL $=0.2$

- Demand for Energy Efficient Lamp = Desire to Conserve Electricity ${ }^{\wedge}$ Elasticity for DfEEL 
Bajracharya and Bhattarai: System Dynamics Modeling of Lighting Electricity Demand in the...

\section{References}

1 Water and Energy Commission Secretariat (WECS), Government of Nepal, (1997). Update and Compilation of Energy Resources and Consumption Profile of Nepal. Final Report, Volume I: Main Report .

2 Water and Energy Commission Secretariat (WECS), Government of Nepal, (1994). Energy Resource and Consumption Profile of the Central Development Region of Nepal. Final Report, Volume I.

3 Water and Energy Commission Secretariat (WECS), Government of Nepal, (2012). National Survey of Energy Consumption and Supply Situation in Nepal. Volume I: Main Report.

4 Ministry of Health and Population (MHP) (2011). Nepal Population Report 2011 Government of Nepal Population Division. Ramshahpath, Kathmandu, Nepal.

5. Economic Survey, (2012). Structure of Energy Consumption. Ministry of Finance, Nepal.

6. Water and Energy Commission Secretariat (WECS), (2012). National Survey of Energy Consumption and Supply Situation in Nepal. Volume 1, Main Report.

7 Water and Energy Commission Secretariat (WECS), (2012). National Survey of Energy Consumption and Supply Situation in Nepal. Volume 1, Main Report.

8 Amatya, V.B., Chandrashekar, M., Robinson, J.B., (1996). Residential sector energysupply-demand analysis: A modeling approach for developing countries and fuel-wood supply sustainability in Nepal. Energy, 18 (4), pp. 341-354.

9 Pokharel, S., 2007. An econometric analysis of energy consumption in Nepal. Energy Policy, 35, (2007), pp. 350-361.

10 Shrestha, R.M., Rajbhandari, S., (2010). Energy and environmental implications of carbon emission reduction targets: Case of Kathmandu Valley, Nepal. Energy Policy, 38 (9), pp. 4818-4827.

11 Bhattarai, N., (2015). National Energy Demand Projection and Analysis of Nepal. Unpublished PhD Dissertation, Department of Mechanical Engineering, Institute for Energy System and Thermodynamics, Vienna University of Technology, Austria.

12 Bhattarai, N., Jha, A., (2015). Commercial sector energy demand projections of Nepal for sustainable sectoral energy planning. Journal of Environment Protection and Sustainable Development, 1 (3), pp. 165-177.

13 Malla, S., (2013). Household energy consumption patterns and its environmental implications: Assessment of energy access and poverty in Nepal. Energy Policy, 61, pp. 990-1002. 
14. Parajuli, R., Østergaard, P.A., Dalgaard, T., et al., (2014). Energy consumption projection of Nepal: An econometric approach. Renewable Energy, 63, pp. 432-444.

15. Forrester, J.W., (1961). Industrial Dynamics. MIT Press, Cambridge.

16. Sterman, J.D., (1981). The Energy Transition And The Economy: A System Dynamics Approach. Unpublished Ph.D Thesis, Department Of Management, Massachusetts Institute of Technology, U.S.A.

17. Bassi, A.M., (2006). Modeling US Energy with Threshold 21 (T21). Accessed : July 2, 2015. Available at: $<$ http://www.millennium-institute.org/resources/elibrary/papers/\%20 US\%20Energy\%20with\%20T21.pdf >

18. Backus, G.A., Amlin, J.S., Kleeman, S., (1995). Energy 2020, Systematic Solutions Inc., Ohio, U.S.A.

19. Naill, R.F., Belanger, S.D., and Kilnger, A. (1990). An Analysis of the cost effectiveness of US energy policies to Mitigate Global warning

20. Chi, K.C., Reiner, D.M., Nuttall, W.J., (2009). Dynamics of UK Natural Gas Industry: System Dynamics Modeling and Long-Term Energy Policy Analysis. EPRG Working Paper 0913. University of Cambridge, Electricity Policy Research Group.

21. Prambndia, Y., Nakano, M. (2010). Scenario Analys of Indonesia .........

22. The U.S. Department of Energy, (1993). An Overview of The IDEAS MODEL. A Dynamic Long-Term Policy Simulation Model of U.S. Energy Supply and Demand.

23. Feng, Y.Y., Chen, S.Q., Zhang, L.X., (2013). System dynamics modeling for urban energy consumption and $\mathrm{CO} 2$ emissions: A case study of Beijing, China. Ecological Modeling 252, pp. 44-52.

24. Olsina, F., Garces, F., Haubrich, H.J., (2006). Modeling long-term dynamics of electricity markets. Energy Policy, 34, pp. 1411-1433.

25. Qudrat-Ullah, H., Dasidsen, P.I., (2001). Understanding the dynamics of electricity supply, resources and pollution: Pakistan's Case. Energy, 26, pp. 595-606.

26. Kayode, O., Nyamapfene, A., (2011). Urban residential energy demand modeling in developing countries: A Nigerian case study. The Pacific Journal of Science and Technology, 12, pp. 152-159.

27. Ministry of Health and Population, Government of Nepal, (2011). Nepal Population Report 2011. Accessed: July 2013. Available : < www.mohp.gov.np/population >.

28. Central Bureau of Statistics (CBS), Government of Nepal, (2014). National Population and Housing Census, 2011. NPHC 2011. 
54 Bajracharya and Bhattarai: System Dynamics Modeling of Lighting Electricity Demand in the...

29. U.S. Energy Information Administration, (2014). Led bulb efficiency expected to continue improving as cost declines. Available at: $<\mathrm{ht} \mathrm{tp://w} \mathrm{w} \mathrm{w.} \mathrm{e} \mathrm{i} \mathrm{a.g} \mathrm{o} \mathrm{v} \mathrm{/}$ todayinenergy/detail.cfm?id=15471>.

30. Sterman, J.D. (n.a.). Business Dynamics

31. Fluorescent, Lamp (n.a.). WIKIPEIA, .....

32. LED Light Bulbs (2015). Comparison Chart ....

33. Nepal Rastra Bank, (2015). Fifth Household Budget Survey, Findings Dissemination Program, Available at: < http://www.nrb.org.np/red/publica_study_reports.php $>$.

34. McPherson, M., Karney, B., (2014). Long -term scenario alternatives and their implications: LEAP model application of Panama's electricity sector. Energy Policy, 68, pp. 146-157.

Note: Views and opinions expressed in this article are the personal views of author. 